\title{
Kamu Diplomasisinin Genișleyen Repertuarı: Medya Okuryazarlığı ve Doğruluk Kontrol Platformları
}

\author{
Mehmet Fatih ÇÖMLEKCุí1
}

\begin{abstract}
Öz
Dijital iletişim ağları dezenformasyonun yayılma hızını artırmakta; devletler, uluslararası örgütler, sivil toplum örgütleri ve diğer baskı grupları ise ortaya çıkan sahte haber sorununa karşı mücadele etmektedir. Bunun yanında, yanlış bilgilerin kasıtlı olarak dolaşıma sokulması, devletler arasındaki "enformasyon savaşı"nın bir parçası olarak da görülmektedir. Çalışmada, doğruluk kontrol platformları ve buna bağı medya okuryazarlığı inisiyatifleri, kamu diplomasisinin dijitalleşmeyle beraber genişleyen repertuarı ve dezenformasyona karşı koymada uygulanan iletişim stratejileri bağlamında ele alınmıştır. Çalışmanın amacı, doğruluk kontrol platformlarının bir kamu diplomasisi aracı olarak nasıl kullanıldıklarını ortaya koymak ve eleştirel bir yaklaşımla bu anlamdaki sınırlııklarını da göstermektir. Bu kapsamda Rusya ile Avrupa Birliği arasındaki enformasyon mücadelesi odağa alınmış, EUvsDisinfo ve StopFake isimli doğruluk platformlarının organizasyonları, hedefleri, yöntemleri ve dijital ortamdaki faaliyetleri kamu diplomasisi teorik çerçevesiyle analiz edilmiştir. Çalışma sonucunda, kamu diplomasisinin dijital aracı olarak kullanılan doğruluk kontrol platformlarının "doğruyu arama" amacının ötesine geçerek, Batılı ülkeler ile Rusya arasındaki enformasyon mücadelesinin bir parçası haline geldikleri ortaya koyulmuştur.
\end{abstract}

Anahtar Kelimeler: Dezenformasyon, Doğruluk Kontrolü, Kamu Diplomasisi, Medya OkuryazarIığı, Sosyal Ağlar.

Atıf: Ç̈mlekçi, M. F. (2020). Kamu Diplomasisinin Genișleyen Repertuarı: Medya Okuryazarlı̆ı ve Doğruluk Kontrol Platformları. Akdeniz Üniversitesi Illetișim Fakültesi Dergisi, 33, s. 211 - 229

1 Öğr. Gör. Dr., Kırklareli Üniversitesi Rektörlük, fatihcomlekci@gmail.com, ORCID Numarası: 0000-0002-4811-5558. 


\title{
The Expanding Repertoire of Public Diplomacy: Media Literacy and Fact-Checking Platforms
}

\begin{abstract}
As digital communication networks increase the spread of disinformation, states, international organizations, non-governmental organizations and other pressure groups have started to fight against the problem of fake news. In addition to that, the deliberate spread of false information has become a tool for the "information war" between states. In this study, fact-checking platforms and associated media literacy initiatives are discussed in the context of the expanding repertoire of public diplomacy with digitalization and communication strategies applied to counteract disinformation. The aim of the study is to reveal how fact-checking platforms are used as a tool of public diplomacy and to show their limitations in this sense with a critical approach. In this framework, the main focus is on the information struggle between Russia and the European Union and thus, the organizations, aims, methodologies and digital activities of the fact-checking platforms named EUvsDisinfo and StopFake have been analyzed within the context of the public diplomacy. As a result of the study, it is concluded that the fact-checking platforms used as the digital tool of public diplomacy have gone beyond the objective of "seeking the truth" and become part of the information struggle between the Western countries and Russia.
\end{abstract}

Keywords: Disinformation, Fact-Checking, Public Diplomacy, Media Literacy, Social Networks.

\section{Giriș}

$\mathrm{D}$ ijital iletişim ağlarının hızlı ve devasa bir enformasyon akışını mümkün kıldığı günümüzde, aslında kitle iletişim araçlarının icadıyla başlayan dezenformasyon ve yanlış bilgilerin yayılması sorunu, yeni bir aşamaya geçmiştir. Yanlış bilgiler özellikle sosyal medya platformları, sahte hesaplar ve çeşitli blog'lar aracılığıyla kullanıcılar tarafından yayılmakla birlikte; bazı devletlerin de çıkarları ve içinde bulundukları enformasyon mücadelesi/savaşı bağlamında dijital araçları kullanarak doğru olmayan bilgileri dolaşıma soktukları sıklıkla dillendirilmeye başlanmıştır (Makhashvili 2017, s. 313; Richey 2018, s. 109-111; Snegovaya 2015, s. 21). Bu çerçevede, gazete, televizyon ve özellikle dijital kanallardan yayılan dezenformasyona karşı sivil toplumun yanı sıra devletler ve uluslararası birlikler de çeşitli karşı koyma ve savunma stratejileri geliştirmektedir. Çalışmada dezenformasyona karşı koyma biçimleri, dijital çağda kamu diplomasisinin genişleyen repertuarı dahilinde ortaya koyulacak; bu bağlamda konu özellikle Rusya ve Avrupa Birliği ile üye ülkeler arasındaki enformasyon mücadelesi çerçevesinde ele alınacaktır.

Kamu diplomasisi odağında değerlendirildiğinde, stratejik iletişim ve dijital araçlardan faydalanma dezenformasyona karşı koyma stratejilerinin temel ayaklarını oluşturmaktadır. Söz konusu pratiklerin bir boyutu medya okuryazarlığını arttırmaya yönelik politikalarla şekillenirken; diğer bir boyutunu ise oluşturulan profesyonel ekiplerle 
uluslararası kamuoyunda dolaşıma giren yanlış bilgileri doğruluk kontrol platformları (fact-checking platforms) yoluyla düzeltmek ve ifşa etmek oluşturmaktadır. Ayrıca, çeşitli medya okuryazarlığı girişimlerine, gazeteci eğitimlerine ve sivil toplum içerisinde gelişen doğruluk kontrol merkezlerine finansal destekler de sağlanabilmektedir.

İşte bu çerçevede çalışmanın amacı, özellikle 21. yüzyılda sosyal medyanın da devreye girmesiyle birlikte artan dezenformasyon sorununa karşı devletler ve uluslararası birlikler nezdinde geliştirilen karşı koyma stratejilerini, dijitalleşmeyle beraber kamu diplomasisinin genişleyen repertuarı bağlamında tartışmaya açmaktır. Doğruluk kontrol platformlarının kamu diplomasisi aracı olarak nasıl kullanıldıklarını ortaya koymak ve eleştirel bir yaklaşımla bu anlamdaki sınırlılıklarını da göstermek temel hedeflerdir. Elbette uluslararası aktörlerin doğruluk kontrolü ve medya okuryazarlığı sahasına girmesi, beraberinde ulusal ve bölgesel aktörlerin çıkarlarının da devreye girmesi sonucunu doğurmaktadır. Bu çerçevede Avrupa Birliği ve üye ülkeler ile Rusya arasındaki enformasyon savaşı/mücadelesini odağa alınacak, konu özellikle EUvsDisinfo ve StopFake isimli doğruluk kontrol platformlarının organizasyonları, hedefleri, yöntemleri, dijital ortamdaki faaliyetleri ve bağlantılı medya okuryazarlığı girişimleri üzerinden ele alınacaktır.

\section{Kamu Diplomasisi ve Dezenformasyon}

Kamu diplomasisi, Josef Nye (2008) tarafından "yumuşak güç" kavramı ile ilişkilendirilmiş, devletlerin çıkarlarına ulaşmak ve "başkalarını" istenen çerçevede tutmak için baskı yerine ilgi çekme ve ikna gibi yöntemlerin kullanılması anlayışı olarak tanımlanmıştır (s. 95). Günümüzde ekonomik gelişmişlik, teknoloji, kültürel birikim ve eğitim gibi faktörler de coğrafi ve askeri varlığın yanında uluslararası gücü arttıran değişkenler olarak görülmektedir. Devletler bu çerçevede kamu diplomasisini, yumuşak gücü oluşturan kaynakları harekete geçirerek, diğer ülkelerin kamuoylarıyla iletişim kanalı kurmak ve onların ilgisini çekmek amacıyla kullanırlar. Yani devletler arasındaki resmi ilişkileri anlatan diplomasiden başka, yabancı ülkelerin halklarına yönelik bir faaliyet söz konusudur (Nye 2008, s. 95). Propagandadan farklı olarak kamu diplomasisinde, doğrudan devlet eliyle yapılan tek taraflı bir enformasyon akışından ziyade, popüler kültür ürünleri, sivil toplum örgütleri ve yurtdışına eğitim için giden öğrenciler gibi çeşitli aracılara başvurulur. Böylece devlet dışı aktörler ülke çıkarları için dolaylı olarak kullanılmakta, bu aracılar diğer ülkelerin sivil toplumuyla onları etkilemek amacıyla ilişkiye geçmektedir. Kurulan bu ilişki sırasında "konuşmak" kadar diğer ülkelerin kamuoyunun sesini "dinlemek" de önemlidir. Bu yüzden tek yönlü değil çift yönlü (karşılıklı) bir iletişim kurmak gereklidir (Nye 2008, s. 101-102).

Nicholas J. Cull'a (2009) göre ise kamu diplomasisi, uluslararası bir aktörün uluslararası çevreyi yabancı kamuoyu ile ilişkiye girerek yönetme/kontrol etme girişimleridir (s. 12). Günümüzde bu uluslararası aktörler devletlerin yanı sıra uluslararası şirketler, uluslararası örgütler ya da sivil toplum örgütleri olabilmektedir. Yine Cull'un (2009) sınıflandırmasına göre kamu diplomasisinin altı temel bileşeni bulunmaktadır. Bunlar: 1) Dinleme (yabancı kamuoyundan bilgi toplama, araştırma yapma), 2) Savunma (ülke 
çıkarlarını korumaya dönük iletişim ve halkla ilişkiler çalışmaları) 3) Kültürel Diplomasi (kültürel kaynak ve başarıları tanıtma) 4) Değişim Programları (öğrenim amaçlı) 5) Uluslararası Yayıncılık (yabancı kamuoylarına radyo, televizyon ve internet aracılığıyla yayın yapma) 6) Psikolojik Savaş (savaş zamanlarında enformasyon mücadelesi yürütme) olarak sıralanabilir (s. 17-22). Yeni kamu diplomasisi anlayışı ile devlet dışı örgütler bu süreçte daha etkili olmakta, dijital araçların kullanımı artmakta, uluslararası iletişim bağlamında marka yaratma stratejileri devreye girmekte ve tek yönlü bir iletişimden çok vatandaşlarla etkileşim kurmaya özen gösterilmektedir (Cull 2019, s. 12-13).

Kamu diplomasisinin bir diğer boyutunu ise, dezenformasyon ve propagandaya karşı koyma, gerçekleri ortaya çıkararak kamuoyunun yanlış yönlendirilmesinin önüne geçme oluşturmaktadır. Kamu diplomasisi uygulamaları kapsamında, propaganda ve özellikle çevrimiçi dezenformasyona karşı, ülke itibarını koruma ve doğru iletişim stratejileri ile politik kriz süreçlerini doğru yönetme amaçlarıyla önemli bir mücadele verilmektedir. Dezenformasyon, karar verici konumdaki kişileri ya da kamuoyunu yanlış yönlendirmek amacıyla, dikkatli bir şekilde oluşturulan ve yanlış bilgiler içeren mesajların hedeflenmiş bir grubun iletişim sistemine gönderilmesi olarak tanımlanmaktadır (Kragh ve Asberg 2017, s. 777-778). Yanlış bilgileri kasıtlı olarak yayanlar, ticari kazanç elde etme, insanları kötü niyetli olarak yanlış yönlendirme ve politik çıkarlara ulaşma gibi farklı motivasyonlara sahip olabilmektedir. Oxford Sözlüğüne (2019) göre ise dezenformasyon, özellikle devlet organizasyonuyla propaganda çalışmaları kapsamında yapılan, rakip bir gücü ya da medyayı yanlış yönlendirmek amacıyla üretilen yanlış bilgidir. Özellikle 2016 yılında ABD Başkanlık Seçimleri ve Birleşik Kralık’taki Brexit referandumu sonrasında, politik kampanyalar sırasında dezenformasyon kullanımı yoğun biçimde tartışılmaya başlanmıştır. ABD'de anket yoluyla yapılan bir kamuoyu araştırmasında, gitgide daha çok vatandaşın seçimlerini/tercihlerini doğru olmayan inanışlara ve yanlış enformasyona dayandırdıkları, kişilerin "olaylardan habersiz" olmadıkları, ancak edindikleri bilginin önemli kısmının "dezenformasyon" kaynaklı olduğu ortaya koyulmuştur (Kuklinski vd. 2014, s. 793). Bu dönemde yayılan sahte ve yönlendirici haberlerin seçmen davranışları üzerinde doğrudan etkili olup olmadığı konusu üzerinde mutlak bir uzlaşma sağlanmamış olsa da, devlet yetkilileri, karar alıcılar ve akademisyenler dezenformasyonun üretimi, tüketimi ve yayılması konularını geniş çaplı olarak ele almaktadır. Ayrıca bu konular iletişim bilimciler tarafından olduğu kadar siyaset bilimciler ve psikoloji alanında çalışanlarca da araştırılmaktadır (Allcott ve Gentzkow 2017, s. 213; Vosoughi vd. 2018, s. 1146-1147).

Nisbet ve Kamenchuk'un (2019) dezenformasyon biçimlerini inceledikleri eserlerinde ilk olarak, sosyal medya platformları, troll hesaplar, blog'lar aracılığıyla ve devasa boyutta yayılan enformasyondan bahsedilmektedir (s. 71-73). Burada amaç hedef kitleyi belirli bir konuda ikna etmekten çok yanlış bilgi ve yalan haberlerle kafa karışıklığı yaratmaktır. Bir diğer dezenformasyon stratejisi de, devlet kontrolündeki uluslararası yayın kuruluşları, sosyal medya hesapları ve internet gazeteleri yoluyla hedef kitleye düzenli olarak yanlış ya da yanıltıcı enformasyonun iletilmesidir. Bu durumda daha uzun vadeli ve hedef kitleyi belirli bir konuda ikna etmeye dönük bir yol izlenmektedir. La Cour (2020) ise devlet aktörleri tarafından yürütülen uluslararası dijital dezenformas- 
yon çalışmalarını üç biçimsel kategoride incelemiştir. İlkinde, yabancı enformasyon çevrelerine iletilen tek bir sahte haber hikâyesi söz konusudur. İkinci olarak ise, birçok sahte hikâyeyi belirli bir strateji dahilinde dolaşıma sokmayı hedefleyen dezenformasyon kampanyaları gelmektedir. Yine yabancı ülkelerin kamuoyunu hedef alan bu strateji dahilinde, belirli bir olay etrafında kafa karışıklığı ve şüphe yaratma söz konusudur. Son olarak ise dezenformasyon operasyonları gelmektedir. Burada ise yabancı ülkelerin kamuoylarını uzun vadeli ve sistematik biçimde yanıltma girişimleri devreye girer. Operasyon kapsamında yayılan her içeriğin ve hikâyenin yanlış olması özellikle gerekli değildir. Önemli olan yaratılan sahte sosyal medya profilleri ve kişilikleri ile yabancı ülkelerdeki vatandaşlar ile etkileşime girerek onları etki altında tutmaktır (s. 1-3)

Konuya uluslararası ilişkiler perspektifinden yaklaşıldığında, tüm bu dezenformasyon stratejileri ülkeler arasındaki "enformasyon savaşı"nın bir parçası olarak da okunabilir. Bu çerçevede özellikle Rusya'nın Ukrayna ve Doğu Avrupa'da yürüttüğü enformasyon çalışmaları (Snegovaya 2015, s. 21; Lupion 2018, s. 330), yine Rusya'nın 2016 ABD seçimlerini manipüle ettiği iddiaları (Howard vd., 2018) ve Çin'in yürüttüğü "enformasyon savaşı" (Brady 2015, s. 51-52; Kania ve Costello 2018, s. 115) çeşitli araştırmalara konu olmuştur. Bu kavram etrafındaki literatür, zararlı enformasyon operasyonlarının dezenformasyonu çoğunlukla siber saldırılar ve dijital sızdırmalar ile nasıl birleştirdiği ile ilgilenmekte; devletlerin buna karşı siber güvenliklerini geliştirme ve enformasyon savaşına karşı koyma biçimlerine odaklanmaktadır. Ancak bu yaklaşım, dijital ortamda yapılan dezenformasyonu modern dijital iletişim ve uluslararası ilişkilerin yeni/özgül bir fenomeni olarak görmediği ve enformasyon savaşı üst kategorisi içine soktuğu gerekçesiyle eleştirilmiştir (La Cour 2020, s. 1).

Yukarıda ifade edilen dezenformasyon stratejilerine maruz kalındığında, devletler nezdinde kamu diplomasisi araçları, vatandaşlar nezdinde ise medya okuryazarlığı girişimleri, söz konusu yanıltıcı/yanlış enformasyona karşı mücadelede kullanılabilmektedir. Devletlerin vatandaşlarına ilköğretimden itibaren sunduğu dijital okuryazarlık eğitimleri, onların yanlış enformasyonu doğru bilgiden ayırmasına yardımcı olabilmektedir. Kamu diplomasisi araçlarını kullanarak dezenformasyon taktiklerini ve sahte haberleri ifşa etme, doğruluk kontrolü platformlarını hayata geçirme, toplumda "hikâyenin aslını" görünür kılma ve yürütülecek kampanyalarla vatandaşların yanlışı doğrudan ayırt edebilecekleri yönünde onlara güven aşılama, bu anlamdaki diğer yöntemler arasında sıralanabilir (Nisbet ve Kamenchuk 2019, s. 71-78).

\section{Avrupa Birliği-Rusya Enformasyon Mücadelesi}

ABD'de 2016 yılında gerçekleştirilen Başkanlık Seçimleri ve Birleşik Krallık’taki Brexit referandumu sonrasında, Rusya'nın enformasyon savaşı vererek ve dezenformasyon çalışmaları yürüterek bu seçimleri etkilemeye çalıştığı iddia edilmiştir (Narayan vd. 2017; Jamieson 2018, s. 20-25). Bunun yanı sıra, Ukrayna ve Gürcistan'ın "Batının” etkisi altına girmesini istemeyen Rusya'nın, hem bu ülkelerin hem de Avrupa Birliği'nin kamuoyuna yönelik dezenformasyon çalışmaları yaptığı konusu da gündeme taşınmıştır (Makhashvili 2017, s. 310-311). Richey’e (2018) göre Rusya'nın yürüttüğü enformasyon savaşının dört temel ayağı bulunmaktadır (s. 109-111). Öncelikle, özellikle 
devlet sahipliğindeki medya aracılığıyla Rusya'nın ve liderlerinin imajları güçlendirilmekte, Rusya'nın çıkarlarını sonuna kadar koruyacak ve düşmanlarına zarar verebilecek kudrette olduğu yönünde uluslararası alanda bir algı yaratılmaktadır. Ikinci olarak ise uluslararası arenada kanun, norm ve politikacılar hakkında güvensizlik yaratma ve böylece "rakip" ya da "düşman" olarak kabul edilen devletlerle halkları arasındaki güveni sarsma hedefi gelmektedir. Bu amaçla gerçeğin ne olduğu ile ilgili kafa karışıklığı yaratma ve internet ile sosyal medya üzerinden tamamen ya da kısmen yanlış olan haberleri/bilgileri yayma gibi yöntemler kullanılabilmektedir. Üçüncü olarak ise, dezenformasyon ve propaganda yoluyla, insan hakları, ulusal egemenlik ve ulusların kendi kaderlerini tayin hakkı gibi konseptleri kullanarak sınır ötesi müdahaleleri söylemsel açıdan meşru hale getirme çabaları gelmektedir. Son olarak da, bilinçli bir enformasyon akışı ile Rusya'ya karşı cephe alan ülkeler içinde ihtilaflar yaratma, buradaki radikal hareketleri destekleme, seçim süreçlerini manipüle etme ve demokratik kurumlara olan kamusal güveni azaltma gibi fiillerden bahsedilmektedir (Richey 2018, s. 109-111).

Makhashvili'ye (2017) göre de Rusya, özellikle Gürcistan ve Ukrayna üzerinden bir enformasyon savaşı yürüterek bu ülkelerin Avrupa Birliği'ne entegre olmasını engellemek istemektedir (s. 312). Tarihsel olarak Rusya'nın etki alanında bulunan bölgelerin AB'nin genişleme politikası ile Batılı ilke ve değerlerin yayılması karşısında tehlike altına girdiğini düşünen Rusya, bu anlamda bölgede kendi gücünü, egemenliğini ve söylemsel üstünlüğünü korumaya gayret etmektedir (Renz ve Smith 2016, s. 1). Ayrıca yine Makhashvili'ye (2017) göre Rusya, AB üyesi ülkelerinde politik polarizasyonu arttırma ve bu ülkelerin birliğe olan aidiyetlerini azaltma yönünde de faaliyet göstermektedir (s. 312). Rusya'nın alternatif anlatılarının farklı ülkelerinin kamuoylarına nasıl bu kadar etkili bir biçimde aktarıldığını inceleyen Steenman (2019) da, ülkedeki katı hiyerarşi ve medya kontrolünün Kremlin yanlısı mesajların yurtdışına belirli kaynaklardan ve belirli bir disiplin içerisinde iletilmesini kolaylaştırdığı sonucuna varmıştır. Snegovaya'ya (2015) göre ise Rusya'nın çevrimiçi "dezenformasyon stratejileri” ve askeri kaynakları gerektirmeyen "enformasyon savaşı", ülkeye finansal açıdan önemli bir yük getirmediğinden uluslararası arenada sıklıkla kullanılan bir araç haline gelmiştir (s. 7). Ayrıca "sahte" haberler, Rusya'nın halihazırdaki kimlik talepleri ve çıkarlarını destekleyen bir söylemin parçası olarak iş görmekte, olaylar hakkında bilgi verme misyonu ikinci planda kalmaktadır. Söz konusu haberler, daha fazla ilgi çekme amacıyla mizah, suçlama, dramatik öğeler ve bağlamından koparılmış görüntülerin kullanımıyla desteklenebilmektedir (Khaldarova ve Pantti 2016, s. 893; Oates 2014)

Rusya ve Ukrayna arasında 2014 yılında başlayan ve Rusya yanlısı hükümetin AB'ye yakın duran başka bir hükümetle değiştiği olaylar üzerine yazan Mejias ve Vokuev (2017) ise, bu süreçte sosyal medyanın dezenformasyonun çok hızlı bir biçimde yayılmasına aracılık ederek sivil toplumun gücünü azalttığını ifade etmiştir (s. 1028). Dezenformasyonun yayılımına farklı bir bakış açısıyla yaklaşan yazarlar, sosyal medya ile birlikte artık devletlerin yanı sıra sıradan vatandaşların da yanlış bilgiler üretebildiği ve bunları çevrelerine yayabildikleri konusu üzerinde durmuşlardır. Özellikle toplumsal hareketliliğin yoğun olduğu zamanlarda dijital platformlar aktivistler tarafından olduğu kadar hareketleri sönümlendirmek isteyen çevrelerce yanlış bilgileri yaymak amacıyla 
da kullanılabilmektedir. Böyle anlarda sıradan vatandaşlar yanlış bilgi, paranoya ve nefret söylemlerini yayan propaganda makinelerine dönüşebilmektedir. Söz konusu yanlış bilgilerin ana-akım medya tarafından alınarak ulusal televizyon ya da gazetelerde yayınlanması da bu tür haberlerin etki alanının genişlemesine yol açmaktadır. Böylece devletler ve ana-akım medya kuruluşları, statükoyu korumak için vatandaşIarın yaydığı yanlış bilgileri araçsallaştırabilmektedir. Mejias ve Vokuev'e (2017) göre dezenformasyon sadece otokratik rejimleri ilgilendiren bir sorun olarak kalmamakta, sosyal medya üzerinden kullanıcı temelli olarak yayılan yanlış bilgiler demokratik toplumları da tehdit eder bir niteliğe bürünmektedir (s. 1039).

Avrupa Birliği de 2015 yılından itibaren sahte haber ve dezenformasyonla mücadele edebilmek için Avrupa Komisyonu ve Avrupa Konseyi çalışmaları çerçevesinde bir görev gücü oluşturmuş, Avrupa'daki seçimlerin "özgür ve adil” şekilde gerçekleşebilmesi için bazı önlemler almaya başlamıştır. Bu kapsamda üye ülkelerle birlikte bazı prensiplerin belirlenmesi ve daha sonra harekete geçilmesi öngörülmüştür. Bu kapsamdaki öncelikler ve yapılacaklar; hızlı uyarı sistemi oluşturarak üye ülkelerin dezenformasyon kampanyalarına karşı birlikte hareket etmelerini sağlamak, Avrupa değerlerinin öne çıkarılmasına dönük stratejik iletişim çalışmaları yürütmek, sahte haberlerle mücadele bağlamında akademisyenleri ve doğruluk kontrol platformlarını desteklemek ve sivil toplumun da desteğini alarak dijital okuryazarlık eğitimlerini arttırmak olarak sıralanabilir (Avrupa Konseyi 2019).

Fried ve Polyakova (2018) tarafından hazırlanan "Dezenformasyona Karşı Demokratik Savunma" başlıklı raporda da, Avrupa Birliği'nin kamu diplomasisinin yürütülmesinden sorumlu birimlerinin iki ana sorumluluğundan bahsedilmiştir. Buna göre, öncelikle, diplomatların ve bürokratların hem birimlerinin hem de kişisel sosyal medya hesaplarını kullanarak yanlış bilgileri ifşa etmeleri ve "doğru" bilgileri ısrarla paylaşmaları gerekmektedir. Bunun haricinde, kendi bünyelerindeki dezenformasyona karşı koyma birimlerini güçlendirerek ve bu amaçla bağımsız sivil kuruluşlarını destekleyerek, doğruluk kontrol platformlarının etki ve görünürlüğünden faydalanmaları gerekmektedir (s. 1-16). Ayrıca söz konusu girişimler, dezenformasyonun tespiti ve ifşası anlamında gazetecilere, editörlere ve çeşitli sivil toplum örgütlerine eğitimler de verebildiğinden maddi olarak desteklenmeleri fayda sağlayacaktır. Bu eğitimlerin ülke geneline yayılması, öğrencilere, kamu görevlilerine ve diplomatlara yönelik dijital medya okuryazarlığı eğitimleri verilmesi de kritik öneme sahiptir (Fried ve Polyakova 2018, s. 9-11).

Bu noktada, kamu diplomasisi teorisyenlerinden Nicholas J. Cull da (2016), "Kremlin propagandası" olarak adlandırdığı enformasyon akışına karşı Batılı ülkelerinin medya okuryazarlığı ve eğitim alanına ağırlık vermesi gerektiğini ifade etmektedir (s. 245). Batı'da ve Rusya'ya komşu olan ülkelerde, medya okuryazarlığı eğitimlerinin geliştirilmesi ve daha iyi bir gazetecilik eğitimi verilmesi gerekmektedir. "Kremlin" tarafından üretilen stereotiplerin tersine çevrilmesi, dezenformasyona karşı koyma stratejilerinin geliştirilmesini de gerekli kılmaktadır (Cull 2016, s. 244). Bu bağlamda 2000'li yıllardan sonra özellikle ABD ve Avrupa'da ortaya çıkmaya başlayan doğruluk kontrol platformları önemli bir yere sahiptir. 


\section{Doğruluk Kontrol Platformları ve Medya Okuryazarlığı}

Demokrasilerin sağlıklı bir biçimde işlemeye devam etmesi için, doğru bilgilerin erişilebilir ve anlaşılabilir olarak vatandaşlara sunulması gerekmektedir. Sosyal medyadan sahte haberlerin hızla yayıldığı, dezenformasyonun sıradan vatandaşlar, politikacılar ya da kanaat önderleri aracılığıyla toplumda dolaşıma sokulabildiği ve politik kutuplaşmanın hat safhada olduğu bir ortamda; doğruluk kontrolü yapan kişi, topluluk ve sivil toplum örgütlerinin çabaları da kritik hale gelmektedir. Böyle bir ortamda ortaya çıkan doğruluk kontrol platformları, gönüllü ya da profesyonel kişilerden oluşan, tarama yaparak kontrol edilecek şüpheli iddiaları seçen, bunlarla ilgili araştırma yapan, gerekirse uzman görüşlerine de başvuran ve sonuç olarak sahte bilgileri ifşa ederek "doğru olanı" kamuyla paylaşan organizasyonlardır (Graves 2017, s. 524).

Doğruluk kontrol platformlarının çabaları medya okuryazarlığı şemsiyesinin altında kendisine yer bulmaktadır. Medya okuryazarlığı, herkesin basılı ve elektronik medya aracılığıyla gelen mesajları deşifre etme, değerlendirme, analiz etme ve bazen de üretme için gereken yeterlilikleri kazanabilmelerinin gerekliliğini işaret eden bir çatı kavramdır (Aufderheide 1993, s. 9-10). Özellikle dijital çağda, hızlı enformasyon akışı karşısında bilinçli tercihler yapabilmek ve medya alanındaki ekonomik ve kültürel ilişkiler çözümleyebilmek önem kazanmaktadır. Bu noktada doğruluk kontrol platformları, dijital ortamda hızla dolaşıma giren haber ve bilgilerin ne kadar doğru ve güvenilir olduklarını ortaya çıkarmaya çalışarak, vatandaşların bu süreçte medya mesajlarını daha sağlıklı değerlendirebilmelerine katkı yapmayı hedeflemektedir. Ünal ve Şahin Çiçeklioğlu'na (2019) göre de doğruluk kontrol platformları, sahte haberlere karşı verdikleri mücadele ile dijital medya okuryazarlığını destekleyici bir unsur olarak öne çıkmaktadırlar (s. 146).

Illk olarak 2000'li yılların başında ABD'de ortaya çıkmaya başlayan doğruluk kontrol organizasyonları, özellikle 2010'lu yıllardan sonra politik kutuplaşmanın artmaya başlamasıyla Avrupa'da çoğalmaya başladı (Humprecht 2019, s. 310). Söz konuşu artışla birlikte bu organizasyonların siyasi konumlanmaları, kullandıkları metodolojiler, yetkinlikleri ve ekonomik şeffaflıkları gibi hususlar da gündeme geldi. Doğruluk kontrol merkezlerinin dayanacağı ilkeleri belirlemek, yöntemler konusunda görüş alışverişinde bulunmak ve iyi örnekleri öne çıkarmak için 2015 yılında Poynter Enstitüsü tarafından kurulan Uluslararası Doğruluk Kontrol Ağı (International Fact-Checking Network), özellikle bu alandaki bağımsız kuruluşlar arasındaki deneyim aktarımını mümkün kıldı. Böylece doğruluk kontrolü konusundaki yeni eğilim ve yöntemleri belirlemek, etik kodlar oluşturmak, konferanslar ve eğitimler düzenlemek gibi imkanlar doğmaya başladı. Bu doğrultuda 2016 yılında yayınlanan "ilke ve Prensipler" metni, kamusal figürlerin, çeşitli kurumların ve toplumda iddiaları dolaşıma giren diğer şahısların açıklamalarının doğruluğuyla ilgili "partizan" olmayan raporlar hazırlayan girişimleri muhatap aldı. Adaletli olma, kaynakların ve kullanılan metodolojinin şeffaflığı ve doğruluk kontrolü sırasında açıklık ile dürüstlük temel ilkeler olarak belirlendi. Söz konusu girişimlerin kendilerini ve birbirlerini değerlendirmeleri sürecinde de IFCN ağının üstleneceği rolün altı çizildi (Pavlevska vd. 2018, s. 7). Sonuç olarak da doğruluk kontrolü pratiklerinin kurumsallaşması, iyileştirilmesi, küresel hale getirilmesi ve bu platformların görünür- 
lüklerinin arttırıması yönünde önemli adımlar atılmış oldu.

Doğruluk kontrol platformları organizasyonel yapıları ve finansmanlarına göre olduğu gibi odaklandıkları alanlara göre de sınıflandırılmaktadır. Buna göre, ilk kategoriyi politik ve kamusal açıklamaların doğruluk kontrolünü yapan, özellikle politikacı ve bürokratların açıklamaları üzerine yoğunlaşan platformlar oluşturmaktadır. Bunun haricinde, çevrimiçi dedikodu ve aldatmacaların ifşa edilmesi ile ilgilenen girişimler de mevcuttur. Son olarak, spesifik bir konu, anlaşmazlık ya da olay üzerine yoğunlaşan platformlar bulunmaktadır (Çömlekçi 2020, s. 276-277). Örneğin Ukrayna sorunu ya da Rusya'nın enformasyon üretimi üzerine yoğunlaşan doğruluk kontrol platformları bu kategoriye dahil edilebilir (Brandtzaeg ve Følstad 2017, s. 65-67). Organizasyonel yapı ve finansman açısından bakıldığında ise; kurumsal medya kuruluşlarının, bağımsız gazetecilerin ve sivil toplum örgütlerinin bu yönde girişimleri olduğu görülmektedir. Yani gazeteciler ve sivil toplum gönüllüleri doğruluk kontrolü pratikleri bağlamında temel aktörler/ özneler olarak öne çıkmaktadır (Graves ve Cherubini 2016, s. 6). Ancak bu noktada bir ayrımın altı çizilmelidir. Medya kuruluşları ve gazetecilerin doğruluk kontrolü pratikleri onların temel habercilik faaliyetlerinin yanında ilerlerken; sivil toplum örgütü modeliyle işleyen bağımsız doğruluk kontrol platformları bunu tam zamanlı bir iş olarak gerçekleştirmektedirler.

Bir diğer önemli nokta ise, doğruluk kontrol platformlarının daha çok insana ulaşmak, onların ilgisini çekmek ve dosyalarının inandırıcılığını arttırmak için kullandıkları dijital araçlar ve veri görselleştirme teknikleridir. Dezenformasyonun ifşası ve doğru bilgilerinin yayılması bağlamında veri görselleştirme yöntemlerinin kullanılması etkili olabilmektedir (Lewandowsky vd. 2012, s. 111). Bu anlamda info-grafik, video, kısa belgesel ve çeşitli görsel materyalin kullanımı, hızın ve görsel kültürün ön plana çıkmaya başladığı sosyal ağlar çağında, okuyucuların ilgisini canlı tutmak için başvurulan yöntemlerden bazılarıdır. Doğruluk kontrol platformlarının görsel materyal kullanımlarının verilen bilgilerin kullanıcı nezdinde daha güvenilir bulunmasına yardım ettiğini gösteren çalışmalar mevcuttur (Amazeen vd. 2016, s. 34; Garrett vd. 2013, s. 621). Ayrıca, videolar yoluyla yapılan anlatımların yine doğruluk kontrol platformlarına olan güveni arttırdığı, kullanıcı ilgisini toplamaya yardım ettiği ve toplanan verilerin video ya da çeşitli veri görselleştirme teknikleriyle sunumunun anlaşılabilirliği arttırdığı görülmüştür (Young vd. 2018, s. 71).

Öte yandan, dijital ortamlarda yayılan dezenformasyon ve sahte haberlerin devletler ve uluslararası örgütler arasındaki "enformasyon savaşı"nın önemli bir aracı haline geldiği yönündeki iddialarla birlikte (Fried ve Polyakova 2018, s. 12; Khaldarova ve Pantti 2016, s. 896), doğruluk kontrol platformlarının dezenformasyona karşı koymada bir kamu diplomasisi aracı olarak kullanılmaya başladığını söylemek de yanlış olmayacaktır. Bu yeni kategoriye, Avrupa Birliği Dış İlişkiler Servisi StratCom Doğu Çalışma Kolu'nun finanse ettiği ve yürüttüğü "EUvsDisinfo" (AB Dezenformasyona Karşı) ve yine Avrupa Birliği'ne üye bazı ülkelerden mali destek gören "StopFake" platformları örnek olarak gösterilebilir. Khaldarova ve Pantti (2016) tarafından da ifade edildiği gibi, internet dezenformasyonun yayılmasına hizmet edebildiği gibi bununla mücadele edecek araçları da sunmakta, çarpıtılmış bilgilerin ve sahte haberlerin/görüntülerin ifşa edilmesi ve böylece karşı-söylemlerin oluşturulmasını kolaylaştırabilmektedir (s. 892). 


\section{Dijital Araçların Dezenformasyona Karșı Kullanımı: "EUvsDisinfo" ve "StopFake"}

"EUvsDisinfo", Avrupa Birliği Dış İlişkiler Servisi StratCom Doğu Çalışma Kolu'nun (European External Action Service East StratCom Task Force) geliştirdiği bir proje olarak 2015 yılında ortaya çıkmıştır. AB Dış İlişkiler Servisi diplomatik bir misyon çerçevesinde kurumun ortak dış siyasetini ve güvenlik politikalarını uygulamakla görevlidir. Ayrıca bu servis dünyanın çeşitli bölgelerinde ofisler ve temsilcilikler açmakta, bulundukları yerlerde AB'yi temsil etme ve onun değerleri ile çıkarlarını koruma görevlerini de üstlenmektedir. StratCom Doğu Çalışma Kolu ve onun ürünü olan EUvsDisinfo projesi de Rusya'nın yürüttüğü ve $A B$ ile üye ülkeleri olumsuz bir biçimde etkilediği iddia edilen "dezenformasyon kampanyaları" ile ilgili öngörülerde bulunmak, bunları gündeme getirmek ve karşılık vermek gibi hedeflerle hayata geçirilmiştir. "Kremlin tarafından gerçekleştirilen dezenformasyon operasyonlarına karşı toplumda farkındalık yaratma" ve "özellikle Avrupa'daki ve diğer ülkelerdeki vatandaşların dijital enformasyon yoluyla yapılan medya manipülasyonlarına karşı koymasına yardım etme”, AB'nin stratejik iletişim politikasının bir parçası olarak değerlendirilen projenin temel amaçları olarak sıralanmıştır. Ancak yine de projenin web sitesinde, yayınlanan dosyaların AB'nin resmi pozisyonunu temsil etmediği, sunulan enformasyon ile ifade edilen görüşlerin çeşitli medya raporları ve StratCom Doğu Çalışma Kolu'nun analizlerine dayandığı ifade edilmiştir (EUvsDisinfo 2019).

Projeyi yürüten ve içerik sağlayan StratCom'da AB kurumlarından ve üye ülkelerden seçilerek işe alınmış 16 tam zamanlı uzman çalışmaktadır. Ekip üyeleri Rusça dahil olmak üzere çeşitli dilleri konuşabilmektedir ve iletişim alanında profesyonel kariyerleri bulunmaktadır. Çalışmaların finansmanı AB Stratejik İletişim bütçesinden karşılanmakta olup, 2018 yılında Rusya'nın “yaptığı” iddia edilen dezenformasyona karşı koyulması için 1,1 milyon Euro bütçe sağlanmıştır. Daha sonra 2019 yılında bu bütçe 3 milyon Euro'ya çıkartılmış, profesyonel medya izleme, dezenformasyon ve veri analizleri için kaynak yaratılmıştır (AB Dış İlişkiler Servisi 2019). Söz konusu kaynak aktarımı, AB hakkında üretildiği iddia edilen dezenformasyon ve "gerçekdışı efsaneleri" ortaya dökerek karşı ve olumlu bir AB söylemi yaratma planlamasıyla yapılmıştır (Giorio 2018, s. 42).

EUvsDisinfo ekibi tarafından "dezenformasyon dosyaları" seçilirken, olgulara dayalı gerçekliğin kısmi, çarpıtılmış ya da yanlış bir versiyonunu sunan ve "Kremlin yanlısı" söylemler ile aynı çizgide olan mesajlara/haberlere odaklanıldığı ifade edilmektedir. Yine projenin kriterlerine göre, seçilen mesajın yanlış ya da yanıltıcı bilgiler içerdiğinin kamuya açık kaynaklar üzerinden ispatlanabiliyor olması ve bu mesajların "Kremlin" tarafından finanse edilen medya organları tarafından dolaşıma sokuluyor olması gerekmektedir. Platformun web sitesinde yayınlanan manifestoda, Rusya tarafından "bilinçli bir biçimde" dolaşıma sokulan dezenformasyon ve yalan haberlerin Batı medyası ile kamuoyuna sızdırılmasının hedeflendiği iddia edilmiştir. Bunu bir tehdit olarak algılayan girişim, kendisine bu mesajların Batı medyasında ve kamuoyunda etki yaratmadan önce tespit ve daha sonra ifşa edilmesi misyonunu yüklemiştir (EUvsDisinfo 2019).

Platform, AB ve AB'nin Doğu Avrupa'da işbirliği yaptığı ülkeleri olumsuz etkilediği düşünülen haberleri veri analizi yöntemleri ve medya izleme servislerini kullanarak tespit 
etmeye çalışmaktadır. Bu çerçevede 15 farklı dildeki materyal taranmaktadır. Üzerinde araştırma yapılan vakalar ve bunların "çürütüldüğüne" dair kanıtlar ise EUvsDisinfo (2019) web sayfasında açık kaynak biçiminde yer almaktadır. Bu web sitesi İngilizce, Almanca ve Rusça dillerinde hizmet vermektedir. Ayrıca web sitesinde platformun kuruluş amacı ve faaliyetleri ile ilgili bilgi veren bir bölüm bulunmakta; kullanıcılar platforma üye olarak içeriklerin düzenli olarak e-postalarına gelmesini sağlayabilmektedir. Bununla beraber web sitesinde kullanıcıların haber ve analizlerle ilgili geribildirimde bulunabildikleri bir form da yer almaktadır. 2019 yılı itibarıyla proje ekibi tarafından incelenen 6.500 haberin/vakanın sonuçları internet üzerinde yayınlanmış ve çevrimiçi veri tabanına eklenmiştir. Veri tabanı yeni araştırma dosyalarıyla her hafta güncellenmekte, ayrıca elde edilen yeni veriler bir bülten haline getirilerek abonelerin e-posta hesaplarına gönderilmektedir. Bunun yanı sıra yeni dezenformasyon yöntem ve pratikleriyle mücadele ile ilgili makale ve analizler yayınlanmakta, alana katkı yapan uluslararası araştırmalar da derlenerek okuyuculara sunulmaktadır (EUvsDisinfo 2019).

ABD Başkanlık seçimleri ve Brexit referandumu sonrasında sıklıkla gündeme gelen, dezenformasyon yoluyla seçimleri manipüle etme iddiaları konusuna da ayrı bir bölüm açılmıştır. Burada demokratik toplumsal yapıyı tehdit eden çevrimiçi manipülasyon ve dezenformasyonla ilgili eğitici dokümanlar yer almaktadır. Kamuyu bilgilendirme çaıışmalarının parçası olarak profesyonellere de eğitimler verilmekte, $A B$ kurumlarına, AB'ye üye devletlerin iletişim profesyonellerine, gazetecilere ve sivil topluma yönelik bilgilendirici programlar hazırlanmaktadır. Böylece çevrimiçi dezenformasyon ve sahte haberlerin dolaşımı konularında dünyanın çeşitli bölgelerindeki politik liderler, devlet kurumları, araştırmacılar, düşünce kuruluşları ve gazeteciler için bir kaynak yaratılmaktadır. Platformun web sitesinin yanı sıra haber ve analiz dosyalarını düzenli olarak paylaşıldığı Twitter ve Facebook hesapları da bulunmaktadır. "Mythbusters" (efsane avcıları) adıyla açılan Twitter ve Facebook hesapları, "Kremlin" tarafından yayıldığı söylenen ve "hayal ürünü" ya da "gerçeklikle bağı zayıf" olduğu ifade edilen haberleri sosyal ağlar üzerinden ifşa ederek daha fazla insana ulaşma amacıyla hareket etmektedir (EUvsDisinfo 2019).

Her ne kadar politik bir motivasyonla ve Rusya'ya karşı yürütülen enformasyon savaşının bir parçası olarak yapılsa da, platformun çevrimiçi dezenformasyona karşı koymayla ilgili eğitici materyallerini dijital medya okuryazarlığı konsepti çerçevesinde değerlendirmek mümkündür. Öncelikle dezenformasyonun nasıl yayıldığı, bu çerçevedeki operasyonların nasıl organize edildiği, sahte hesaplar vasıtasıyla yanlış bilgilerin hangi yollarla dolaşıma sokulduğu ve bunlara nasıl meşruluk kazandırıldığı üzerinde durulmaktadır. Daha sonra ise "enformasyon savaşı" kapsamında Rusya'nın RT (Russian Today) ve Sputnik gibi kamu fonlu medya organları gündeme getirilmekte, bunların çok farklı dillerde ve formatlardaki (tv kanalı, web sitesi, Youtube kanalı, vb.) yayınlarıyla dezenformasyona dayalı geniş bir medya ekosistemi yarattıkları iddiası dillendirilmektedir (EUvsDisinfo 2019). Rusya'nın 2016 ABD Başkanlık seçimleri, 2017 Fransa ve Almanya seçimleri ile Brexit referandumuna çeşitli çevrimiçi taktikleri kullanarak müdahale ettiği iddialarıyla ilgili araştırmalar da platformun veri tabanında kendine yer bulmuştur. Bennett ve Livingston'a (2017) göre, söz konusu seçim dönemlerinde sahte haberler yayarak ulaşılmak istenen amaçlar, kurumsal düzeni bozmak, politikacıların 
saygınlığını azaltmak, göçmen karşıtı bir kamuoyu oluşturmak ve seçimler öncesinde seçmenlerde bir kafa karışıklığı yaratmak olarak özetlenebilir (s. 130). Bu sahte haberler ve göçmen karşıtı propaganda; ortada kültürel bir savaş olduğu, göçmenlerin entegre olamayacağı ve güvenlik tehdidi oluşturdukları varsayımlarından hareket etmektedir (Juhasz ve Szicherle 2017, s. 1). Özetle sahte haberler, seçimleri manipüle etme, göçmenlere karşı bir söylem üretme ve demokratik kurumların altını oyma gibi birtakım olumsuz işlevleri yerine getirebilmektedir.

Söz konusu tehdide karşı ilk önlem alan devletlerden biri olan Almanya, sosyal medyadaki sahte haberlere ve nefret söylemine karşı "Netzwerkdurchsetzungsgesetz" isimli yasayı çıkararak, sosyal medya platformlarının bu türdeki içerikleri kaldırmasını sağlama yönünde adım atmıştır. Ayrıca, Avrupa Birliği çatısı altında, devlet ya da devlet dışı aktörler tarafından organize edilebilen, siber saldırı, finansal manipülasyon ve dezenformasyon kampanyaları için sosyal medyayı kullanarak politik söylemi kontrol etme, böylece kişileri/aktörleri radikalleştirmeyi içinde barındıran "hibrid tehditler" ile mücadele için bir yol haritası çıkartılmıştır (European Commission 2016). İşte Avrupa Birliği'nin dezenformasyona karşı dijital platformları kullanarak işlevsel hale getirdiği doğruluk kontrol platformu EUvsDisinfo da, bu mücadele bağlamında ve dünya kamuoyuna yönelik olarak AB'nin çıkarlarına dönük bir kamu (dijital) diplomasi aracı olarak değerlendirilmelidir.

Söz konusu projede üretilen içeriklerin dili ve sunuluş biçimleri de zaman zaman bazı tartışmalara konu olmaktadır. AB Dış İlişkiler Servisi tarafından 2016 yılında yazılan bir parlamento raporunda, EUvsDisinfo projesi kapsamındaki içerik üretiminin Uluslararası Gazeteciler Federasyonu standartlarına uygun olması ve saldırgan dil kullanımı ile değerleri yargılayıcı üsluptan uzak durulması konularında bazı uyarılar yapıımıştır (Fotyga 2016, s. 12). Yine aynı raporda düşülen bir şerh ise, projenin Rusya ile olan politik kutuplaşmayı daha fazla arttırabileceği ve "saldırgan" bir söylem kullanılırsa bu girişimin kendisinin de bir propaganda aracına dönüşebileceği yönünde olmuştur (Giorio 2018, s. 55-56). Projeyle ilgili soruların cevaplandığı resmi web sitesinde de, bu minvalde gelen eleştirilere cevap vermek amacıyla, ekibin temel görevinin propaganda yapmak değil "Avrupa'nın doğusundaki bölgelere AB projelerini doğru biçimde açıklamak" olduğu ifade edilmiştir. Ayrıca ekibin dezenformasyonu tespit ve if̧̧a etme sorumluluğunu taşıdığı, medyada dolaşan verilerin doğruluğunu araştırdığı ve mesajı gönderen ile değil mesajın kendisiyle uğraştığı vurgulanmıştır (AB Dış İlişkiler Servisi 2019).

Doğrudan devlet ya da uluslararası kuruluş destekli olmasa da, Ukrayna konusundaki "sahte haberleri" konu alan ve genel olarak Rusya tarafından yayılan enformasyona karşı pozisyon alan StopFake isimli doğruluk kontrol platformu ise bir diğer örnektir. Ukrayna'daki bir sivil toplum örgütü olan Medya Reform Merkezi tarafından 2014 yılında kitle kaynaklı olarak kurulan platform, daha sonra Çekya Dış İşleri Bakanlığı, Ukrayna'daki Birleşik Krallık ve Kuzey İrlanda Büyükelçilikleri ve Birleşik Krallık Dış İşleri Bakanlığı² (Foreign and Commonwealth Office) tarafından finansal olarak desteklen-

2 Mevcut çalışmanın tamamlanmasından sonra, 31 Ocak 2020 tarihinde Birleşik Krallık Avrupa Birliği'nden resmen ayrılmıştır. 
miştir. Bu durum platformun web sitesinde açık bir biçimde belirtilmiştir (StopFake.org 2019). Girişim kapsamında Ukrayna'daki gazetecilerin profesyonel eğitim düzeylerinin ve toplumun genelindeki medya okuryazarlığı seviyelerinin yükseltilmesi, propagandanın ve sahte haberlerin tehlikelerine karşı vatandaşların bilgilendirilmesi temel amaçlar olarak belirlenmiştir. Bu amaçlara ulaşmak için Ukrayna ile ilgili yanlış bilgilerin taranması, tespit edilmesi, konuyla ilgili araştırma yapılması ve doğru bilgilerin web sitesi üzerinden yayınlanması aşamalarından geçilmektedir. Doğruluk kontrolü Rusça, Ukraynaca ve İngilizce dahil olmak üzere 13 farklı dilde yapılmakta, elde edilen sonuçlar web sitesinin yanında çevrimiçi videolar, televizyon kanalları, radyo podcast'leri ve sosyal medya siteleri aracılığıyla da kamuoyuna ulaştırılmaktadır.

İkinci aşama ise medya okuryazarlığı ve haber/bilgi doğrulama araçları ile ilgili eğitim dokümanlarının yayınlanması, konu hakkında farkındalık yaratmaya yönelik etkinlik, çalıştay ve konferansların düzenlenmesi ile sivil aktivistler ve blogger'lara eğitimler verilmesi gibi unsurlardan oluşmaktadır. Platformun web sitesine bakıldığında, sahte haberlerle ilgili analizlerin yanı sıra konu hakkındaki bilimsel araştırma, köşe yazıları, bilgilendirici videoların ve medya okuryazarlığına dönük eğitici oyunların yer aldığı görülmektedir. Bir diğer önemli nokta ise, kullanıcıların kendi başlarına doğru bilgiyi sahte/yanlış olandan ayırmaları için gereken dijital araçların tanıtılmasıdır (StopFake. org 2019). Dijital medya okuryazarlığı kapsamındaki bu eğitsel girişimler, kamuoyunu sahte haber olgusu hakkında bilgilendirmenin yanında vatandaşların dikkatini çekme, farkındalık yaratma ve kendilerini bu alanda geliştirmelerini sağlama amaçlarını da gütmektedir. Kamu diplomasisindeki yumuşak güç anlayışıyla paralellik arz eden bu girişimler, esas olarak, uluslararası kamuoyunu Rusya'nın yaptığı iddia edilen dezenformasyona karşı uyarmak ve onları bu konuda korunaklı hale getirmeyi öncelik haline getirmektedir. Bunun yanında, kullanıcılar da platforma şüpheli gördükleri haberleri değerlendirmeleri için gönderebilmekte, yaptıkları bağışlarla finansal açıdan destek sağlayabilmektedirler. Böylece organizasyon ile kullanıcılar arasında bir etkileşim sağlanmaktadır. Bahsedilen kullanıcı etkileşimi ve katıımı, kamu diplomasisinin teorisyenlerinden olan Nye'nin (2008), kamu diplomasisinde hedef kitleyi dinleyerek çift yönlü (karşılıklı) bir iletişim kurmanın gerekliliği yönündeki ifadeleriyle de örtüşmektedir (s. 101-102).

StopFake'in doğruluk kontrolü pratiklerine bakılacak olursa, "Kremlin tarafından yayılan dezenformasyon ve propaganda"nın analiz edilmesi temel hedef olarak belirlenmiştir. Bu anlamda Ukrayna ilgili olarak yayıldığı iddia edilen sahte haber ve bilgilere ağırlık verilse de, dezenformasyonun Avrupa Birliği üyesi ülkeler ile Sovyetler Birliği'nden ayrılan ülkeleri nasıl etkilediği konuları da araştırılmaktadır. Bu hedeflerden de anlaşılabileceği gibi, "StopFake" girişimi ve "EUvsDisinfo" örneği Avrupa Birliği ve onu destekleyen ülkeler ile Rusya arasındaki etki alanı mücadelesinin enformasyon ile ilgili olan boyutunun çıktıları olarak ön plana çıkmaktadır. Her iki doğruluk kontrol platformu da Rusya aracılığıyla yayıldığı söylenen dezenformasyona karşı durma iddiasındadır ve doğrudan ya da dolaylı olarak Avrupa Birliği üyesi ülkeler tarafından finanse edilmektedir.

EUvsDisinfo ve StopFake örneklerinde görülen bir diğer ortak özellik ise, bu girişimlerin hazırladıkları doğruluk kontrolü dosyalarını uluslararası kamuoyu ile çeşitli dijital 
platformlar yoluyla paylaşırken, veri görselleştirme, video ve info-grafik hazırlama gibi yenilikçi yöntemlere başvurmalarıdır. Böylece doğruluk kontrolleri sadece metin olarak okuyuculara sunulmamakta, verilerin görselleştirilmesi yoluyla hedef kitlenin ilgisini çekme, onların mesajları kolayca alımlayabilmelerini sağlama ve böylece daha fazla kişiye ulaşma stratejileri izlenmektedir. Kamu diplomasisinin temel amaçlarından birinin hedef kamuoyunun ilgisini çekme ve mümkün olduğunca fazla kişiye istenen mesajı iletme olduğu düşünüldüğünde; dijital imkanlarla tasarlanan bu yeni araçlar hedef kamuoyuyla diyalog ve etkileşim bağlamında yeni imkanlar sunmaktadır.

Sözü edilen doğruluk kontrol platformları ve bu kapsamda faaliyet gösteren çalışma ekipleri, eğitimler düzenleyerek ve eğitici materyaller hazırlayarak medya okuryazarlığının artııılmasına yönelik çalışmalar yürütebildikleri gibi; Avrupa Birliği üyesi ülkeler kendi eğitim sistemleri içerisinde de yabancı kaynaklı dezenformasyona karşı önlem alma yoluna gidebilmektedir. Fried ve Polyakova'nın (2018) ifadeleriyle, sivil eğitim ve medya okuryazarlığı dersleri/eğitimleri Batı'nın dezenformasyona verdiği yanıt olmalıdır (s. 13). Kamusal eğitim kampanyaları hem sivil toplum hem de politik liderler tarafından desteklenmeli; medya okuryazarlığına odaklanacak eğitimler sosyal medyadaki ve çevrimiçi diğer içeriklere karşı eleştirel düşünme yetisini geliştirmeye yönelik yapılandırılmalıdır. Bu çerçevede Finlandiya'nın eğitim sistemi ve ilköğretimden itibaren müfredata eklenen çevrimiçi dezenformasyona karşı koyma dersleri örnek olarak gösterilebilir. Rusya'nın uluslararası politik çıkarları çerçevesinde etki alanında tutmaya ve NATO'ya üye olmasını engellemeye çalıştığı Finlandiya, 2014 yılından sonra Rusya'nın bu amaçla ürettiği "sahte haberlere" maruz kaldığı iddiasını gündeme getirmiştir (Henley 2020). Finlandiya hükümeti de bu anlamda bir "enformasyon savaşı" içerisinde olduklarını kabul etmiş, dezenformasyon kampanyalarının ülke içindeki etkisini azaltmaya dönük çalışmalar yürütmüştür. İşte bu kapsamdaki medya okuryazarlığı eğitimleri ile ilköğretimden başlayarak öğrencilere eleştirel düşünme, doğruluk kontrolü yapma, alınan enformasyonu doğru yorumlama, propagandayı ve yanıltıcı haberleri ayırt etme pratikleri kazandırımaya çalışıımaktadır. Finlandiya, Uluslararası Medya Okuryazarlığı Endeksi'nde 2018 yılında birinci sırada yer alarak bu anlamda kayda değer bir ilerleme göstermiştir (Henley 2020; Fried ve Polyakova 2018, s. 13). Özetle, Avrupa Birliği ve üye ülkelerin Rusya menşeili olduğunu iddia edilen dezenformasyona karşı kamu diplomasisi çerçevesinde aldığı önlemlerde, doğruluk kontrolü platformlarının faaliyetleri ve medya okuryazarlığı eğitimleri iç içe geçmiş durumdadır.

\section{Sonuç ve Tartıșma}

Çalışmada görüldüğü üzere, doğruluk kontrol platformları ve buna bağlı olarak hayata geçirilen medya okuryazarlığı inisiyatifleri, dezenformasyona karşı kamu diplomasisi aracı olarak kullanılabilmektedir. İster "EUvsDisinfo" örneğinde olduğu gibi doğrudan uluslararası örgüt ya da devletler tarafından kurulmuş olsun, ister "StopFake" örneğinde görüldüğü gibi halihazırda sivil toplum içinde faaliyet gösteren bir girişim maddi açıdan desteklensin, doğruluk kontrol platformlarının kamu diplomasisinin dijitalleşmeyle birlikte genişleyen repertuarının bir parçası haline geldiğini söylemek mümkündür.

Bunun yanında, hazırlanan doğruluk kontrolü dosyalarının birçok farklı dilde yayınla- 
narak hedef ülke ve dünya kamuoyuna hitap edilmesi, devlet ya da uluslararası örgüt çıkarlarını savunurken "doğru" enformasyonun bir araç olarak kullanılması ve genel olarak dijital imkanların kullanımı bu çabaları kamu diplomasisinin "yumuşak güç" kavramı içerisinde değerlendirmeyi mümkün kılmaktadır. Cull'un (2019) sıraladığı yeni kamu diplomasisinin altı özelliğinden ikisi olan, "çıkarların iletişim süreçleriyle savunulması" ve "uluslararası yayıncılık" bu anlamda açıklayıcıdır. Küresel çapta ve çok farklı dilde yayın yapan doğruluk kontrol platformları "dezenformasyona" karşı "doğru" bilgileri yayarak çıkar savunuculuğu yapmakta ve web sitesi, çevrimiçi video kanalları ve sosyal ağlar aracılığıyla dünya kamuoyuna yönelik "uluslararası yayıncılık" faaliyeti gerçekleştirmektedir. Bu anlamda geçmişte küresel etki yaratmak için kullanılan gazete ve televizyon gibi geleneksel kamu diplomasisi araçlarının yerini internetin ve sosyal ağların almaya başladığını söylemek mümkündür (s. 31-32). Ayrıca, yeni kamu diplomasisinde konuşmak kadar dinlemenin ve karşılıklı ilişki (etkileşim) kurmanın önemini vurgulamıştır (Nye 2008, s. 101-102; 2010). Bu çerçevede kullanıcılardan geri dönüş toplayan, sosyal medya platformlarını kullanan ve kendini ulaşılabilir hale getiren doğruluk kontrol platformları, dijitalleşen kamu diplomasisini temsil eden araçlardan biri olarak öne çıkmaktadır. Ayrıca internet üzerinden yapılan yayınlarda videoların, çeşitli görsellerin, veri görselleştirme tekniklerinin ve info-grafiklerin kullanımı, doğruluk kontrolü dosyalarını ilgi çekici hale getirerek daha geniş bir kitle üzerinde etkili olma amacına hizmet etmektedir.

Öte yandan, kamu diplomasisi bağlamında araçsallaştırılan doğruluk kontrol platformlarının diğer bağımsız girişimlerden iki noktada farklılaştığı görülmektedir. Öncelikle bu platformlar, sadece Kremlin'in yaydığını iddia ettikleri dezenformasyona odaklanarak ve kendilerini "karşı tarafa" konumlandırarak, salt gerçeğin ortaya çıkarılması motivasyonundan öte Rusya'ya ve genel olarak dünya kamuoyuna yönelik bir "yumuşak güç" inisiyatifi olarak öne çıkmaktadırlar. Böylece bu platformlar, sadece kamuoyunu doğru bilgilendirme gibi bir idealle hareket etmekten öte, ülkeler ve uluslararası örgütler arasında gerçekleşen enformasyon mücadelesinin birer aracı olarak kullanılmaktadırlar. Aslında bu girişimleri sadece araştırmacı gazetecilik ve veri gazeteciliği pratiklerinin uygulandığı platformlar olarak değil, "çıkar savunuculuğu yapan stratejik iletişim projeleri” bakış açısıyla değerlendirmek de mümkündür. StopFake isimli platform EUvsDisinfo örneğinin aksine doğrudan bir uluslararası örgüt ya da devlet tarafından kurulmamış, bağımsız bir girişim olarak hayata geçmiş ve kullandığı metodoloji ile kaynakları konusunda şeffaflık ilkesini benimsemiştir. Ancak hem Batılı devletlerden gördüğü maddi destek (Cull 2019, s. 31-32) hem de kendisini sadece tek bir konuya ("Kremlin propagandası") odaklaması, bu platforma da Rusya karşısında bir "taraf" haline gelen kamu diplomasisi aracı görünümünü vermektedir.

İkinci olarak ise, devlet ve uluslararası kuruluşların desteklediği doğruluk kontrol platformları, sivil toplum ve bağışçıların sürüklediği bağımsız organizasyonlardan farklı olarak finansal açıdan resmi kaynaklara bağımlı hale gelmektedir. Söz konusu durum, finansman kaynağı olan ülke ya da uluslararası kuruluşların çıkarlarıyla çelişen doğruluk kontrolü çalışmalarının ne ölçüde bu platformlarda yer alabileceği sorusunu gündeme getirmektedir. Özellike EUvsDisinfo örneğinde gördüğümüz, doğrudan Avrupa Birliği'ne üye ülkelerin sağladığı personel ve maddi kaynak ile kurulan bir doğruluk 
kontrolü girişiminde; tarafsız doğruluk kontrolü, araştırmacı gazetecilik ve "karşı propaganda" arasındaki sınırlar bulanık hale gelmektedir. Sadece Rusya'ya karşı konumlanan ve sadece "Kremlin" kaynaklı olduğu iddia edilen dezenformasyonu gündemine alan platformların, tek misyonu "doğruyu" ortaya çıkarmak olan girişimler olarak değil de Rusya ile Batılı ülkeler arasında devam eden enformasyon savaşının/mücadelesinin bir cephesi olarak görülmesi mümkündür.

Son olarak ise, kamu diplomasisi aracı olarak değerlendirilen dijital doğruluk platformlarının, daha geniş bir "medya okuryazarlığı" projesinin parçası olma niteliği taşıdıkları vurgulanmalıdır. Özellikle AB destekli olarak 2015 yılından sonra başlayan sahte haberlere ve dezenformasyona karşı koyma eylem planları; bazı Batılı ülkelerde medya okuryazarlığı eğitimlerinin ilköğretimden itibaren verilmeye başlanması, bu kapsamda gazetecilerin ve vatandaşların bilgilendirilmesi, yanlış bilgiyi doğrudan ayırt etmeye yarayacak dijital araçların tanıtılması gibi adımların atılmasına önayak olmuştur. İşte bu çerçevede dijital ortamda faaliyet gösteren doğruluk platformları da, Batının dezenformasyona karşı koyma, medya okuryazarlığı seviyesini artırma, uluslararası kamuoyuna "doğru" mesajları yollayarak çıkarlarını ve küresel imajını koruma araçlarından biri halini almıştır. Ancak bu türdeki girişimler objektif ve bağımsız biçimde doğruluk kontrolü yapma hedefinden uzaklaşarak sadece tek taraflı bir çıkar savunuculuğu aracı haline geldiklerinde, toplumdaki politik kutuplaşmayı arttırma ve uzun vadede saygınlıklarını yitirme gibi olumsuz sonuçlarla da karşı karşıya gelebilirler. Doğruyu ortaya çıkarma misyonuna sahip her türlü girişim geniş bir toplumsal kabul görmek için şeffafıık, adil olma, tarafıııktan kaçınma ve objektiflik gibi bazı temel ilkeleri benimsemelidir.

\section{Kaynakça}

AB Dış Ilişkiler Servisi. (2019). Questions and Answers about the East StratCom Task Force. 12 Aralık 2019 tarihinde https://eeas.europa.eu/headquarters/headquarters-homepage/2116/questions-and-answers-about-the-east-stratcom-task-force_en adresinden edinilmiştir.

Allcott, H., ve M. Gentzkow. (2017). Social Media and Fake News in the 2016 Election. Journal of Economic Perspectives 31 (2), $211-236$.

Amazeen, M. A., Thorson, E., Muddiman, A., ve Graves, L. (2018). Correcting Political and Consumer Misperceptions: The Effectiveness and Effects of Rating Scale Versus Contextual Correction Formats. Journalism \& Mass Communication Quarterly, 95(1), 28 - 48.

Aufderheide, P. (1993). Media Literacy. A Report of the National Leadership Conference on Media Literacy. Aspen Institute, Communications and Society Program, 15 Aralık 2019 tarihinde https://files.eric.ed.gov/fulltext/ED365294.pdf adresinden edinilmiştir.

Avrupa Konseyi. (2019). Securing free and fair European elections: Council adopts conclusions. 15 Aralık 2019 tarihinde https://www.consilium.europa.eu/en/press/press-releases/2019/02/19/ securing-free-and-fair-european-elections-council-adopts-conclusions/ adresinden edinilmiştir.

Bennett, W. L., ve Livingston, S. (2018). The disinformation order: Disruptive communication and the decline of democratic institutions. European journal of communication, 33(2), 122 - 139. 
Brady, A. M. (2015). Authoritarianism goes global (II): China's foreign propaganda machine. Journal of Democracy 26(4), 51 - 59.

Brandtzaeg, P. B., ve Følstad, A. (2017). Trust and distrust in online fact-checking services. Communications of the ACM, 60(9), 65 - 71.

Cull, N. J. (2009). Public diplomacy: Lessons from the past. Los Angeles, CA: Figueroa Press.

Cull, N. J. (2016). Engaging foreign publics in the age of Trump and Putin: Three implications of 2016 for public diplomacy. Place Brand Public Diplomacy, 12, 243 - 246.

Cull, N. J. (2019). The Tightrope to Tomorrow: Reputational Security, Collective Vision and the Future of Public Diplomacy. The Hague Journal of Diplomacy, 14(1-2), 21 - 35.

Çömlekçi, M. F. (2020). Combating Fake News Online: Turkish Fact-Checking Services. In Dalkir, K., \& Katz, R. (Eds.), Navigating Fake News, Alternative Facts, and Misinformation in a Post-Truth World (pp. 273-289). IGI Global.

EUvsDisinfo. (2019). 24 Aralık 2019 tarihinde https://euvsdisinfo.eu/ adresinden edinilmiştir.

European Commission. (2016) Joint framework on countering hybrid threats, 24 Aralık 2019 tarihinde http://eur-lex.europa.eu/legal-content/EN/TXT/?uri=CELEX\%3A52016JC0018 adresinden edinilmiştir.

Fotyga, A. E. (2016). Report on EU Strategic Communication to Counteract Propaganda against It by Third Parties. Committee on Foreign Affairs, 1-22., 12 Aralık 2019 tarihinde http://www. europarl.europa.eu/doceo/document/A-8-2016-0290_EN.pdf adresinden edinilmiştir.

Fried, D., ve Polyakova, A. (2018). Democratic defense against disinformation. Washington, DC: Atlantic Council. 14 Aralık 2019 tarihinde https://disinfoportal.org/wp-content/uploads/ ReportPDF/Democratic-Defense-Against-Disinformation.pdf adresinden edinilmiştir.

Garrett, R. K., Nisbet, E. C., ve Lynch, E. K. (2013). Undermining the corrective effects of media-based political fact checking? The role of contextual cues and naïve theory. Journal of Communication, 63, 617 - 637.

Giorio, L. (2018). War on Propaganda or PRopaganda War?: A case study of fact-checking and (counter) propaganda in the EEAS project EUvsDisinfo. $10 \mathrm{Kasım} 2019$ tarihinde http://uu.divaportal.org/smash/record.jsf?pid=diva2\%3A1252061\&dswid=-592 adresinden edinilmiştir.

Graves, L., ve Cherubini, F. (2016). The Rise of Fact-Checking Sites in Europe. Oxford, UK: Reuters Institute for the Study of Journalism.

Graves, L. (2017). Anatomy of a fact check: Objective practice and the contested epistemology of fact checking. Communication, Culture \& Critique, 10(3), 518 - 537.

Henley, J. (2020). How Finland starts its fight against fake news in primary schools. The Guardian. 29 Ocak 2020 tarihinde https://www.theguardian.com/world/2020/jan/28/fact-fromfiction-finlands-new-lessons-in-combating-fake-news adresinden edinilmiştir.

Howard, P. N., B. Ganesh, D. Liotsiou, J. Kelly, ve C. François. (2018). The IRA, Social Media and Political Polarization in the United States 2012-2018. 24 Aralık 2019 tarihinde https:// comprop.oii.ox.ac.uk/wp-content/uploads/sites/93/2018/12/The-IRA-Social-Media-and-Political- 
Polarization.pdf adresinden edinilmiştir.

Humprecht, E. (2019). How Do They Debunk "Fake News"? A Cross-National Comparison of Transparency in Fact Checks, Digital Journalism, 8(3), 310 - 327.

Jamieson, K. H. (2018). Cyberwar: how Russian hackers and trolls helped elect a president: what we don't, can't, and do know. Oxford: Oxford University Press.

Juhász, A., ve Szicherle, P. (2017). The political effects of migration-related fake news, disinformation and conspiracy theories in Europe. Budapest: Friedrich Ebert Stiftung, Political Capital.

Kania, E. B., ve J. K. Costello. (2018). The strategic support force and the future of chinese information operations. The Cyber Defense Review 3 (1), 105 - 122.

Khaldarova, I., ve Pantti, M. (2016). Fake news: The narrative battle over the Ukrainian conflict. Journalism Practice, 10(7), 891 - 901.

Kragh, M., ve Åsberg, S. (2017). Russia's Strategy for Influence through Public Diplomacy and Active Measures: the Swedish Case. Journal of Strategic Studies, 40(6), $773-816$.

Kuklinski, J. H., P. J. Quirk, J. Jerit, D. Schwieder, F. Robert, ve R. F. Rich. (2000).

Misinformation and the Currency of Democratic Citizenship, The Journal of Politics, 62(3), 790 -816 .

La Cour, C. (2020). Theorising digital disinformation in international relations, International Politics, DOI: https://doi.org/10.1057/s41311-020-00215-x

Lewandowsky, S., Ecker, U. K., Seifert, C. M., Schwarz, N., ve Cook, J. (2012). Misinformation and its correction: Continued influence and successful debiasing. Psychological science in the public interest, 13(3), 106 - 131.

Lupion, M. (2018). The gray war of our time: Information warfare and the kremlin's weaponization of Russian-language digital news. The Journal of Slavic Military Studies 31 (3), $329-353$.

Makhashvili, L. (2017). The Russian information war and propaganda narratives in the European Union and the EU's Eastern Partnership countries. International Journal of Social Science and Humanity, 7(5), 309 - 313.

Mejias, U. A., ve Vokuev, N. E. (2017). Disinformation and the media: the case of Russia and Ukraine. Media, Culture \& Society, 39(7), 1027 - 1042.

Narayanan, V., Howard, P. N., Kollanyi, B., ve Elswah, M. (2017). Russian involvement and junk news during Brexit. Computational Propaganda Project, Data Memo. 22 Aralık 2019 tarihinde http://comprop.oii.ox.ac.uk/wp-content/uploads/sites/89/2017/12/Russia-and-Brexit-v27.pdf adresinden edinilmiştir.

Nisbet, E. C., ve Kamenchuk, O. (2019). The Psychology of State-Sponsored Disinformation Campaigns and Implications for Public Diplomacy. The Hague Journal of Diplomacy, 14(1-2), $65-82$.

Nye, J. S. (2008), Public diplomacy and soft power. The Annals of the American Academy of 
Political and Social Science, 616(1), 94 - 109.

Nye, J. S. (2010). The new public diplomacy, project syndicate. 12 Aralık 2019 tarihinde https:// www.project-syndicate.org/commentary/the-new-public-diplomacy?barrier=accesspaylog adresinden edinilmiştir.

Oates, S. (2014). Russian State Narrative in the Digital Age: Rewired Propaganda in Russian Television News Framing of Malaysia Airlines Flight 17. Political Communication PreConference at George Washington University, Washington, DC. 12 Aralık 2019 tarihinde http:// www.media-politics.com/presentationspublications.htm adresinden edinilmiştir.

Oxford Sözlüğü (2019). 10 Aralık 2019 tarihinde https://www.lexico.com/en/definition/ disinformation adresinden edinilmiştir.

Pavleska, T., Školkay, A., Zankova, B., Ribeiro, N., ve Bechmann, A. (2018). Performance analysis of fact-checking organizations and initiatives in Europe: A critical overview of online platforms fighting fake news. Social media and convergence, 1 - 29.

Renz, B. ve Smith, H. (2016). Russia and Hybrid Warfare - Going Beyond the Label, Aleksanteri Papers, 1 - 19.

Richey, M. (2018). Contemporary Russian revisionism: understanding the Kremlin's hybrid warfare and the strategic and tactical deployment of disinformation. Asia Europe Journal, 16, $101-113$.

Snegovaya, M. (2015). Putin's information warfare in Ukraine. Soviet Origins of Russia's Hybrid Warfare', Russia Report, 1, $1-28$.

Steenman, J. (2019). To what extent is societal (de) securitization present in the practices of EuVsDisinfo in the Netherlands and the EU? (Yayımlanmamış yüksek lisans tezi) Leiden: Leiden University International Relations Department.

StopFake.org. (2019). 24 Aralık 2019 tarihinde https://www.stopfake.org/en/about-us/ adresinden edinilmiştir.

Ünal, R., ve Çiçeklioğlu, A. Ş. (2019). The Function and Importance of Fact-Checking Organizations in the Era of Fake News: Teyit. Org, an Example from Turkey. Media Studies, 10(19), 140 - 160.

Vosoughi, S., Roy, D., ve Aral, S. (2018). The Spread of True and False News Online. Science 359, $1146-1151$.

Young, D. G., Jamieson, K. H., Poulsen, S., ve Goldring, A. (2018). Fact-checking effectiveness as a function of format and tone: Evaluating FactCheck. org and FlackCheck. org. Journalism \& Mass Communication Quarterly, 95(1), 49 - 75. 